\title{
A new competency ontology for learning environments personalization
}

\author{
Gilbert Paquette $^{1^{*}} \mathbb{D}$, Olga Marino ${ }^{2}$ and Rim Bejaoui ${ }^{1}$
}

\section{*Correspondence:}

gilbert.paquette@licef.ca

${ }^{1}$ Laboratory for Instructional

and Cognitive Engineering

(LICE), LICEF Research Center,

Université TÉLUQ, Quebec,

Canada

Full list of author information

is available at the end of the

article

\begin{abstract}
Competency is a central concept for human resource management, training and education. We define a competency as the capacity of a person to display a generic skill with a certain level of performance when applied to one or more knowledge entities. Competencies, and competency referentials grouping competencies, are essential elements for user models, e-Portfolios, adaptive learning, and personalization in Technology-based learning. But to be processed both by humans and by software tools, competencies should be represented in a formal, non-ambiguous model called an ontology. Moreover, this model should use a shared vocabulary to describe the generic skills and the knowledge entities. Defining and linking shared vocabularies is the purpose of ontologies in the semantic web. The goal of our research is to develop a competency ontology for the semantic web to be used as a shared referential in the description of competencies and competency profiles. We analysed five previous competency models and developed COMP2, a new competency ontology that integrates important elements of previous models and the richness of the semantic web vocabulary. COMP2 provides processing capabilities both to humans and computers. Its graphic model is highly readable by humans for design, evaluation and communication purposes. It also translates, together with its data sets, to standard semantic Web code for machine processing. The ontology is composed of five stages that are interlinked with other ontologies in use within the web of linked open data. We will present an example for the use of the ontology for competency-based personalization in learning environments.
\end{abstract}

Keywords: Competencies, Competency models, Competency ontologies, Technology-based learning, Personalization, Web of linked open data, Semantic web, Human competency management

\section{Introduction}

Acquiring new competencies is a central goal of any education or knowledge management process. Ministries of education, school boards and teacher training institutes use competency profiles to define the goals of school programs or courses. Consulting companies present their expertise by enumerating their competencies, marketing their services in this way. Organisations and companies use guidelines or computerized tools to manage the competencies of their staffs, considered as their main asset. Governmental party material in this article are included in the article's Creative Commons licence, unless indicated otherwise in a credit line to the material. If material is not included in the article's Creative Commons licence and your intended use is not permitted by statutory regulation or exceeds the permitted use, you will need to obtain permission directly from the copyright holder. To view a copy of this licence, visit http:// creativecommons.org/licenses/by/4.0/. 
agencies or professional associations use them to define and prepare professional training programs to maintain professional expertise.

\section{The need for formal competency models}

Competency-based education, as well as competency-based knowledge management in organizations, both require a competency profile grouping related competencies in a

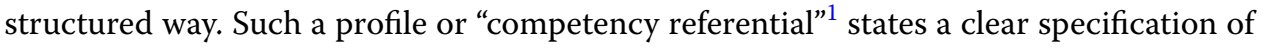
target competencies to be attained by a curriculum or a course, or for the execution of professional work in an organization. It provides specific goals to learning or work activities and criteria for learner's or worker's observation and evaluation, enabling a systematic assessment of competency acquisition. There exist now a large number of specific competency profiles in subjects as diverse as Data science (Hattingh et al., 2019), Health (Princy \& Rajeswari, 2019), Education (Gadušová, 2019), Human Resources (Dubois et al., 2000) and information Technology (SFIA, 2019).

Unfortunately, much confusion surrounds the notion of competency and most of the competency referential are informal natural language statements unfitted for software management. This explains why they are seldom used as software support for competency management, outside laboratories and research projects.

Some authors define competency as a general characteristic of a person as diverse as skill, ability, self-image, social role, or knowledge. Le Boterf (1999, p. 38) defines a competent person as "[..] someone who knows how to act appropriately in a particular context by mobilizing a double resource base: personal resources (knowledge, abilities, personal qualities, culture, emotions, etc.); and network resources (databases, documents, expert networks, etc.). Knowing how to act appropriately means being able to perform a set of activities according to certain desirable criteria". While this definition is insightful on the theoretical aspect of competency, it does not provide a formal model usable in software environments.

A number of competency definitions and competency profiles have been proposed in the last 15 years (Srivastava \& Vikram, 2014) for specific knowledge domains. In most of the implementations we have consulted, a competency is expressed as a simple natural language sentence, which is inherently informal and ambiguous. Competency profiles are a collection of these sentences, where semantic relations such as prerequisite relations are not explicit and any two competencies are difficult to compare. To be used in software environments for education or knowledge management, competency and competency profiles must be instances of a formal model that can be managed computationally.

Modeling competencies and competency profiles is at the core of some research projects and innovations for educational learning environments (CAEL, 2017): for personalizing the recommendation of learning resources according to competency-based user models (Yago et al., 2018); to give assistance to learning scenarios or business processes based on competencies; to build and manage e-portfolios of evidence of competency

\footnotetext{
1 Throughout this paper, both terms will be used as synonyms, as a set of competencies, even though "competency profile" are usually used as an attribute of a person, while "competency referential" is a set of competencies in use in an organisation.
} 
acquisition (Moulet et al., 2008); to identify competency gaps by comparing competencies possessed by users with those involved in learning resources or tasks (da Silva, Jerónimo \& Vieira, 2019); to develop competency assessing methods; and assure interoperability of competency profiles from different sources (Dolog \& Schäfer, 2005). All these projects have used some kind of formal competency models.

Having a formal, unambiguous explicit representation of competencies and competency profiles is fundamental, on one hand, to be able to build, maintain, validate and interconnect all these software innovations. On the other hand, such representations should be understood in a non-ambiguous way by human users and shared by the concerned community. This leads us to the need of formal competency models for software applications, that are instances of a competency ontology (Braun et al., 2012). Our goal here is to build such a high level ontology.

\section{Ontologies and the semantic web}

The leading current technology for formally representing, manipulating and sharing knowledge is the Semantic Web and its main components: the ontologies. (Allemang \& Hendler, 2011; Domingue et al., 2011). An ontology can be defined as a formal, explicit specification of a shared conceptualization, composed of concepts and relations between them (Gruber, 1993). Ontologies are at the core of the Semantic Web and its more recent flavor, the Web of open and linked data. At the beginning of the century, (Berners-Lee et al., 2001) proposed an extension for the Web, where unified resource identifiers $\left(\mathrm{URIs}^{2}\right.$ ), would represent not only pages of information but all kind of entities such as people, real-world objects and also abstract concepts. To represent meaning or knowledge behind web pages of information, these entities would be connected through properties (also represented by URIs), composing knowledge graphs of interconnected entities or vocabulary elements. Thus, the main purpose of the Semantic Web is to introduce explicit descriptions about the meaning of resources, to allow the machines themselves to have a level of understanding of the Web's content.

Although domain ontologies offer great opportunities, the whole power of the Semantic Web is reached when these domain ontologies are open, freely accessible and interconnected creating a cloud of linked open data (LOD, 2017; Schmachtenberg et al., 2014; ONTOTEXT, 2017). The Linked Open Data (LOD) community, which started in 2007 with just a few open datasets published under Linked Data principles, has become a large space containing more than 1200 datasets (each linked to various ontologies) containing billions of RDF triples. Among LOD datasets, the term "Knowledge Graph" (KG) refers to big cross-domain graph-based knowledge databases such as OpenCyc, Freebase, Wikidata, DBpedia, and YAGO.

These datasets, as well as many others, are connected through inter-ontology links. For example, the term "person" in the FOAF (Friend-of-a-Friend) ontology describing peoples' properties, is declared as equivalent to the term "person" in DBpedia, as well as to the same term in GEOBASE, another ontology that provides geographical information about persons. Suppose an educational resource has a specified author like Hubert

\footnotetext{
${ }^{2}$ URI extend the Web addresses or Uniform Resource Locators (URLs) that all of us use in our daily lives.
} 
Reeves, it enables a search on the web-LOD for information on this author that would retrieve automatically his Wikipedia pages from DBpedia, his email and the other resources he has authored from FOAF, and also his geographical residence location from GEOBASE data. The web of linked open data enables software agents or human agents to follow the links and perform more intelligent inferences using the knowledge behind the words stored in the URIs and their links. (Heath and Bitzer, 2011).

Our purpose here is to build a general Semantic web ontology for competencies and competency profiles. Users of this competency ontology will be able to use it to specify particular ontologies for various knowledge domains. These in turn will enable to build formally defined datasets describing the competencies of peoples, resources or activities that can be processed by software applications on the web of linked data.

\section{Goal and methodology of the research}

In this paper, we build a competency ontology defined in terms of the RDFS ontology language, applying the principles of the Semantic Web. This ontology needs to have three main properties.

- First, it must be generic to be specialized for any competency profile or model, and in any subject or knowledge domain.

- Second, it should be flexible in its use, meaning it can encompass a large variety of educational or knowledge management applications where competencies are associated to persons and resources can be expressed, compared and assessed.

- Third, it should take into account and have connections with the growing number of educational vocabularies and ontologies that populate the web of linked open data.

In this research, we started with a previous competency model that we have developed and that has been used successfully in a number of applications by our laboratory and other groups, and we analysed several other competency models to enrich it. Our research is based on Ontological Engineering principles, a field providing methods to build ontologies. The work by Uschold and King (1995) is considered as the first effort towards developing a methodology for building ontologies. (Casellas, 2011) has reported a list of 20 documented ontology engineering methodologies.

The present research is based on the Neon Methodology framework (Suárez-Figueroa et al., 2015). This framework proposes several scenarios particularly suited for reusing, enriching and integrating existing formal or non-formal representations. We took into account two main scenarios proposed in this framework: scenario 2 and scenario 5. Scenario 2 is designed for the reuse and reengineering of non-ontological resources and was used for the transformation into formal representations of our previous competency model (COMP1) and some of the other models analyzed in this paper. Scenario 5 gives guidelines for the integration of several representations and was considered when integrating elements from the different models to create the new COMP2 competency ontology. In particular, it enabled us to build and compare five model proposals and identify similarities to guide the developement of COMP2. 
We divided the ontology development process into five steps: steps 1 to 3 follow scenario 2 guidelines of the NEON framework while steps 4 and 5 follow scenario 5 recommendations:

1- Transform our initial competency definition into a formal ontology, COMP1, using an ontology graphic language (Resource Description Framework Schema-RDFS), within the framework of the Semantic web;

2- Identify and analyze other generic formal models in the literature in order to discover new concepts and relations;

3- Transform descriptions of these models into ontologies using the same graphic modeling language as in COMP1, to enable their comparison;

4- Identify meta-features of the competency ontologies modeled in step 1 and 3 by a comparative analysis of the semantics displayed in the five ontology graphs;

5- Use these meta-features to guide the construction of a new competency ontology named COMP2; here we followed a top-down development approach, first focusing on the central components down to several other related concepts and properties.

"A first formal competency ontology" section will cover Step 1 to provide a knowledge graph for our initial COMP1ontology. Steps 2, 3 and 4 will be addressed in "Comparing competency models to build the requirements" section where we compare the five ontology models and identify important meta-features. This result will guide the last step, providing the main result of the research: the definition of the COMP2 ontology, that will be presented in "COMP2, a new competency ontology" section. "Competencybased personalization of learning environments" section will present an example of the use of this ontology, while the conclusion will identify further work to assess further the validity of the COMP2 ontology.

\section{A first formal competency ontology}

Based on our own extensive research on the conceptual and practical dimensions of competency modelling (Author, ref 1), we developed a first competency model that has been used for more than 15 years, to define competency referentials for course design or for professional organizations (lawyers, accountants, physicians) and in software, energy and banking companies, either using the MISA Instructional Design Method (Author, ref 2) or the TELOS (Authors, ref 10) system for knowledge management to which the competency model has been integrated as a component.

This first competency generic model (Author, ref 4) was not based on Semantic Web (SW) technologies, but it has been regularly consulted and sometimes reused by other researchers such as (Rezgui et al., 2014). So we think it has been validated enough to serve partly in a new SW-based ontology. In this section, we will transform this initial competency model to create a formal ontology within the framework of the Semantic web of linked open data.

\section{The initial competency information model}

In the initial model, a competency was defined as the capacity of a person to display a generic skill (or attitude), with a certain level of performance, when applied to one or 
more knowledge entities. The association of skill and knowledge within a competency statement makes it possible to specify which of the cognitive, affective, social and psychomotor processes must be mobilized to process knowledge.

For example, suppose we state that a technician can diagnose the faults in a car engine, for all kinds of cars. This is a competency where a technician applies the "diagnose" generic skill (a kind of analysis) to knowledge on "faults in a car engine", with a degree of performance " for all kinds of cars". A lower level of competency would be to "diagnose only certain kinds of car", while a upper level would be to "repair" the car. Comparison between competencies have proven very important for instructional engineering (Authors, ref 5), in order to identify competency gaps.

Our initial competency model included an elaborated taxonomy of generic skills that generalizes Bloom's taxonomy and taxonomies in software and cognitive engineering on problem solving expertise. ${ }^{3}$ Skills are ordered on a scale from simple to complex generic skills. Also, performance indicators such as frequency, scope, autonomy, complexity and context ${ }^{4}$ can be combined to classify the competency into one of four performance classes: A-awareness, B-familiarization, C-productivity or D-expertise, or alternatively to situate the competency on a performance scale from 1 to 10 . The two scales for skill and performance served to compare manually any two competencies placed on a twodimensional scale.

\section{Moving the competency model to the Semantic web level}

The knowledge graph of Fig. 1 results from the transformation of this initial competency model into an ontology. It has been produced using the GMOT visual modeling language and $\operatorname{tool}^{5}$ (Author, ref 6). GMOT graphs can be automatically translated into Extensible Markup Language (XML) ontology formats such as RDFS or Ontology Web Language (OWL), which can be processed by software agents to provide a variety of services.

An important difference between this COMP1 ontology and our initial non-SWbased model is the integration of popular web-LOD vocabularies, such as (SKOS, 2009), (FOAF, 2014), (DCMI, 2012) and (RDFS, 2014). Some of the classes or properties in the COMP1 model are linked to corresponding well-defined terms in these vocabularies.

For example, a competency can be related with another one by a subsumes (S) property declared as a sub-property of a SKOS broader transitive property, thus gaining a precise meaning defined in the W3C SKOS reference document. Also, a domain ontology is defined as a SKOS concept scheme designed to represent RDFS or OWL ontologies as well as less elaborated knowledge schemes such as thesauri or taxonomies, thus adding flexibility to the notion of a "domain ontology". The Skill's taxonomy and the

\footnotetext{
${ }^{3}$ See for example the pioneering work of Chandrasekaran (1987) and the KADS methodology (Breuker and Van de Velde, 1994) that propose a taxonomy of problem solving methods and corresponding expertise or skills identified in Artificial engineering and Knowledge management research.

4 These performance indicators and their combination have stem out of many research on Instructional Design; their combination has been validated in a number of competency-based applications. See (Author, ref 3). An ontology and a software framework for competency modeling and management.

${ }^{5}$ In the Graphic Modeling with Object Types (GMOT) visual models in this paper, rectangles represent classes; object properties (labeled on links) are related by " $\mathrm{R}$ " links from their domain class and to their range class; data properties are related by " $R$ " links from their domain class and to a data type; the " $S$ " link is used both for sub-class and sub-property relations, and the "I" link relates a class to its instances.
} 


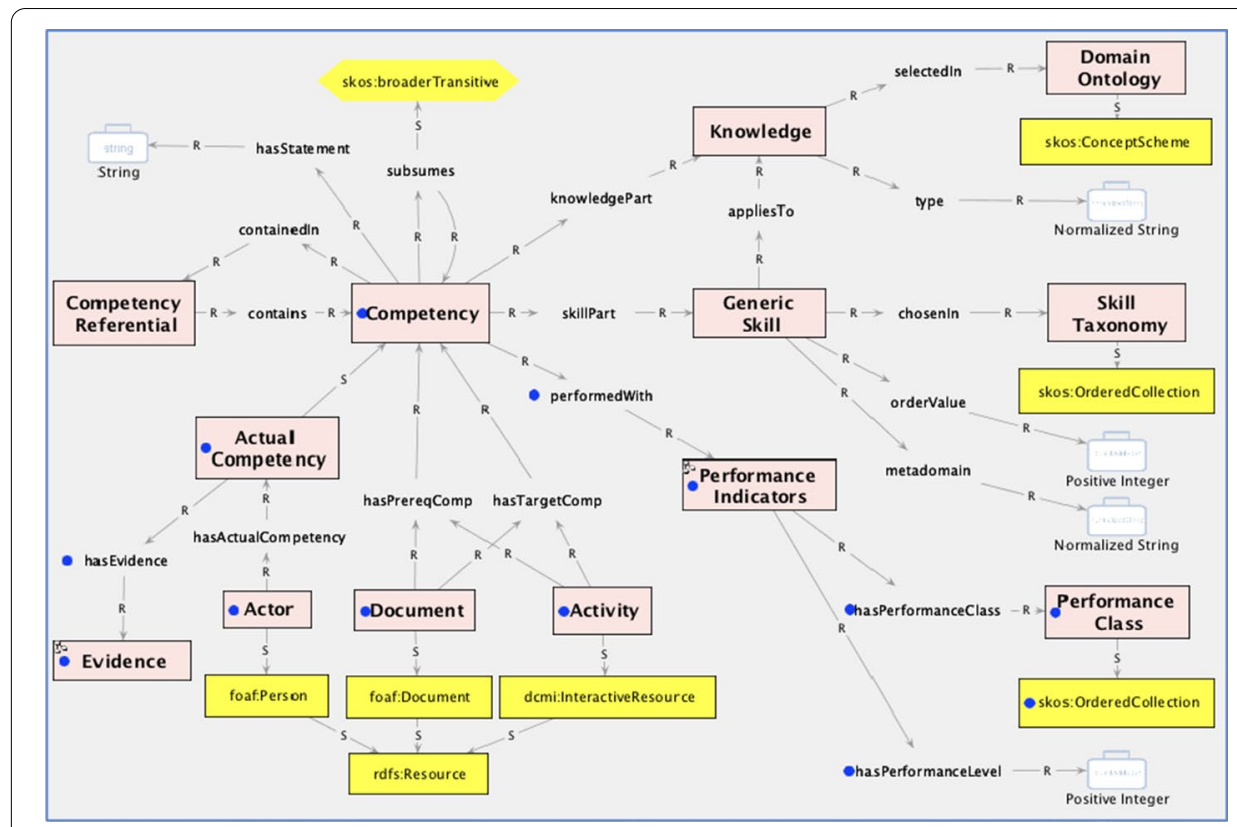

Fig. 1 A RDFS model for the COMP1 ontology

Performance Classes are both defined here as skos:OrderedCollections, also defined precisely in the SKOS definition document.

Another improvement, not present in our initial competency model, is the association of competencies to actors, documents and activities in a learning scenario, defined respectively as sub-classes (S links) of foaf:Person, foaf:Document and dcmi:interactiveResource. Documents and activities have prerequisite and target competencies chosen in some Competency Referential (or profile). On the other hand, actors have actual competencies, chosen in a Competency Referential that includes competencies associated to an actor. Each actual competency for an actor has supporting Evidence that can take many forms: documents produced, activities achieved, other actors appraisals (for example in open badges)..

\section{Comparing competency models to build the requirements}

To validate and improve this initial COMP1 ontology, we have search the literature for related efforts.

\section{Related efforts to build generic competency models}

Even though there are many competency or profiles for particular subjects in the literature, we found only a few generic competency proposals abstracted from particular domains that could be transformed in SW ontology format, which is our goal in this research. The following four generic competency models have been analyzed.

\section{- The IEEE RCD standard and the IMS RDCEO specification}

The Reusable Competency Definition (IMS RDCEO, 2002; IEEE RCD, 2004, 2007) enables interoperability among learning systems that deal with competency infor- 
mation by providing a mean for them to refer to common definitions with common meanings.

- The HR-XML Competency model

Created by the industry-led HR-XML consortium on open standards, the HR-XML Competency data model (Allen et al., 2001) provides users with a standardized and practical way to exchange information about competencies from various business contexts, also providing links to various Human Resource management activities.

- The Achievement Standards Network Description Language (ASN-DL)

This extensive ontology model contains 38 properties and 10 classes within an RDFS model (ASN-DL, 2012), well integrated in the web-LOD. Its goal is to provide computer-based encoding and interoperability of the competencies repositories (or profiles) defined by states and provinces in U.S. and Canada for K-12 education.

- The Rezgui et al. competency ontology.

Rezgui et al. (2014) proposed a comprehensive generic competency model, taking into account three important dimensions: structure of a competency (based on our own initial model presented in "The initial competency information model" section), proficiency measure of an individual's performance, and the context in which the competency is applied or acquired (Sampson \& Fytros, 2008; Sampson, 2009).

\section{Analysis of the models}

To be able to compare these four models and our COMP1 model in a fair and precise way, we analyzed thoroughly their documentation and built four corresponding competency ontology models in SW RDFS format, using the same visual modeling language and tool that helped describe the COMP1 model in Fig. 1. The analysis process involved aligning corresponding terms in all five ontologies, considering their respective contexts to find out their meaning using ontological engineering principles (Suárez-Figueroa et al., 2015).

This analysis has enabled us to identified 10 meta-features present or absent from the five competency models. The comparative analysis of these ontology models, summarized in Fig. 2, have helped us define the requirements for the new COMP 2 competency model we intended to build.

- Model format. The first two competency models (RDCEO and HR-XML) did not provide semantic information and did not use semantic web (SW) languages. They are focused mainly on describing any competencies in a standard way to enable the interoperability of competency profiles. The other three models use the RDFS language, sometime extended with OWL elements. They also provide some links to other semantic web vocabularies.

- Competency format. RDCEO, HR-XML and ASN-DL present competencies as natural language strings that can represent either knowledge, skills, attitudes, or a combination of these. They provide no internal structure for the competency. This corresponds to a general practice in most competency profiles. COMP1 and Rezgui ontologies also associate natural language statements to a competency 


\begin{tabular}{|c|c|c|c|c|c|}
\hline \multirow[t]{2}{*}{ Model Features } & \multicolumn{5}{|c|}{ Competency Model or Ontology } \\
\hline & RCD/RDCEO & HR-XML & ASN-DL & COMP1 (TELOS) & REZGUI \\
\hline Model format & $\begin{array}{l}\text { Metadata Relational } \\
\text { Model }\end{array}$ & $\begin{array}{l}\text { Metadata Relational } \\
\text { Model }\end{array}$ & RDFS Ontology & RDFS Ontology & RDFS Ontology \\
\hline Competency format & $\begin{array}{l}\text { Natural language } \\
\text { statement }\end{array}$ & $\begin{array}{l}\text { Natural language } \\
\text { statement }\end{array}$ & $\begin{array}{l}\text { Natural language } \\
\text { statement }\end{array}$ & $\begin{array}{l}\text { Internal structure as a } \\
\text { KSP triple + Natural } \\
\text { language string }\end{array}$ & $\begin{array}{l}\text { Internal structure as } \\
\text { KSPC quadruplet + } \\
\text { Natural language }\end{array}$ \\
\hline $\begin{array}{l}\text { Association between } \\
\text { competencies }\end{array}$ & None & $\begin{array}{l}\text { Limited to a subsume } \\
\text { taxonomy }\end{array}$ & $\begin{array}{l}\text { Elaborated map of } \\
\text { associations }\end{array}$ & $\begin{array}{l}\text { Limited to a subsume } \\
\text { taxonomy }\end{array}$ & $\begin{array}{l}\text { Subsumes, composed } \\
\text { of, requires, similar to }\end{array}$ \\
\hline $\begin{array}{l}\text { Skill association to } \\
\text { competency }\end{array}$ & $\begin{array}{l}\text { Skill is some kind of } \\
\text { competency }\end{array}$ & $\begin{array}{l}\text { Skill is some kind of } \\
\text { competency }\end{array}$ & $\begin{array}{l}\text { Link between } \\
\text { competency and skill }\end{array}$ & $\begin{array}{l}\text { Skill (skos concept) is } \\
\text { part of a competency }\end{array}$ & $\begin{array}{l}\text { Skill (skos concept) is } \\
\text { part of a competency }\end{array}$ \\
\hline $\begin{array}{l}\text { Knowledge } \\
\text { association to } \\
\text { competency }\end{array}$ & $\begin{array}{l}\text { Knowledge is some } \\
\text { kind of competency }\end{array}$ & $\begin{array}{l}\text { Knowledge is some } \\
\text { kind of competency }\end{array}$ & $\begin{array}{l}\text { Knowledge is some } \\
\text { kind of competency }\end{array}$ & $\begin{array}{l}\text { Knowledge (skos } \\
\text { concept) is part of a } \\
\text { competency }\end{array}$ & $\begin{array}{l}\text { Knowledge (skos } \\
\text { concept) is part of a } \\
\text { competency }\end{array}$ \\
\hline $\begin{array}{l}\text { Performance/ } \\
\text { Proficiency scale }\end{array}$ & None & Competency weight & $\begin{array}{l}\text { Level in a proficiency } \\
\text { scale }\end{array}$ & $\begin{array}{l}\text { Links to performance } \\
\text { criteria, class and level }\end{array}$ & $\begin{array}{l}\text { Links to performance } \\
\text { criteria, class and level }\end{array}$ \\
\hline $\begin{array}{l}\text { Link to documents } \\
\text { and activities }\end{array}$ & None & None & $\begin{array}{l}\text { Multiple kinds of } \\
\text { correlation links }\end{array}$ & $\begin{array}{l}\text { Prerequisite and target } \\
\text { competency links }\end{array}$ & $\begin{array}{l}\text { Link to ePorfolio } \\
\text { resource }\end{array}$ \\
\hline $\begin{array}{l}\text { Link to actors and } \\
\text { learners }\end{array}$ & None & $\begin{array}{l}\text { Link to owner of the } \\
\text { compentency }\end{array}$ & None & $\begin{array}{l}\text { Actual competency link } \\
\text { to learner and } \\
\text { facilitator }\end{array}$ & $\begin{array}{l}\text { Actual competency link } \\
\text { to learner and } \\
\text { facilitator }\end{array}$ \\
\hline $\begin{array}{l}\text { Evidence of } \\
\text { acquisition }\end{array}$ & None & $\begin{array}{l}\text { Multiple evidence } \\
\text { properties }\end{array}$ & $\begin{array}{l}\text { Assessed competency } \\
\text { link from a resource }\end{array}$ & $\begin{array}{l}\text { Many to many link with } \\
\text { evidence sources }\end{array}$ & $\begin{array}{l}\text { Properties of evidence } \\
\text { record and evidence } \\
\text { source }\end{array}$ \\
\hline $\begin{array}{l}\text { Context of } \\
\text { acquisition }\end{array}$ & None & User Area & $\begin{array}{l}\text { Standard document } \\
\text { properties }\end{array}$ & Learning scenario & $\begin{array}{l}\text { Has context properties } \\
\text { link to a skos concept }\end{array}$ \\
\hline
\end{tabular}

Fig. 2 Competency ontology comparison

object but provide a structural definition for the statement, respectively as a triple (skill, knowledge, performance) or as a quadruple of elements (skill, knowledge, performance, context).

- Association between competencies. Except RCD/RDCEO, all the models provide a subsume relationship between competencies. ASN-DL provide in addition an extensive set of six kinds of "alignments" between competencies (minor, major, narrow, broad, prerequisite and exact) inspired by the SKOS ontology, while Rezgui provides three possible associations (prerequisite, composed of, similar to), in addition to the subsume relationship provided by COMP1.

- Skill association to a competency. In RCD and HR-XML, a skill is seen as some kind of competency so no relation is provided between a competency and a skill. In ASN, an association can be made between a statement (a competency) and an "embodied skill”. In Rezgui, skill is a kind of a SKOS concept, which means that skills are not ordered, contrary to COMP1 that considers a skill as chosen in a SKOS ordered collection. This feature is essential to define gaps between two competencies according to their skill level.

- Knowledge association to a competency. In the first three models, knowledge is also seen as some kind of competency, so there is no association of a knowledge entity to a competency. Again, in Rezgui, knowledge is associated to a SKOS concept, while in COMP1, competency is associated to a "knowledge part" selected in a "domain ontology", which is a SKOS concept scheme that provides a structure between knowledge entities, providing another way to compare competencies.

- Performance/Proficiency scale. In RCD, no such term is provided. In HR-XML, there is a scale of "competency weights" for proficiency levels. In ASN, COMP1 and in Rezgui, there is an explicit competency property for a "proficiency level" chosen in 
a "proficiency scale". COMP1 and Rezgui models contain also concepts for "performance indicators" and for a "performance class" derived from the performance indicators.

- Association of competencies to documents and activities. In RCD and HR-XML there is no such association. ASN-DL present the most elaborated set of associations called "correlations". There are nine such types of correlation between a learning resource and a competency statement that are sub-properties of the Dublin core "conforms to" property. In COMP1, documents and activities have prerequisite and target competency properties. In Rezgui there is a link from a competency to an ePortfolio resource and to documents or activities serving as "evidence" of competency acquisition.

- Association of competencies to actors. In RCD, HR-XML and ASN-DL there is no such associations, because the competency profiles are at the organisation level, business or school. COMP1 has an explicit property from an actor to to its "actual competency", which is selected in the "competency profile". In Rezgui, there is a direct link from a "competency record" (associated to a competency) to an actor, the later being linked to an "evidence record".

- Evidence of acquisition. This concept is absent from RCD. In HR-XML and COMP1, there is a not a very well developed evidence concept associated to a competency. In ASN, there is no explicit evidence concept, but an "assessed competency" property associating an assessment results resource to a competency statement. In Rezgui, there is a well-developed "evidence record" associated to a competency record, both with a "confidence rating" property; the evidence record is associated with an "evidence source" that can be a resource, an activity, an evaluation or a personal development plan.

- Context of acquisition. RCD do not provide such concepts. COMP1 provide a link to a "competency profile" that indicates its origin. HR-XML associates a competency to an explicit concept of "user area". Rezgui has a context property linked to a SKOS concept. ASN-DL provides the context of acquisition of the competency through the properties of a "standard document" that contains the competency profile.

\section{Guidance principles for a competency ontology.}

Considering the roles of a competency ontology for the design of learning or knowledge management software environments, as well as the the meta-features discussed above, we now state some guidance principles for the construction of the COMP2 ontology.

Processing capability - The ontology should provide processing capability both for humans and machines. In particular, competency assessment is a collaborative process were some tasks can be performed by computer programs and others by human peers, tutors or managers. Elements of a competency ontology should thus be easily readable by humans, and also provide an information format to be processed by software tools. In the RCD and HR-XML models, competencies are essentially narrative, unstructured pieces of text that render machine processing difficult (Idrissi et al., 2020). An ontology model, as proposed by the ASN, COMP1 and Rezgui models, should be preferred to less structured information models, in order to capture the meaning of the terms and 
maximise the inference capabilities. The ontology and its knowledge base must enable processing, interoperability and reuse of competency definitions in large organisation networks (Sicilia et al., 2014).

Large scope-The ontology should have a sufficiently large scope to provide all the necessary components to construct useful competency referentials (or profiles) in various contexts. The RCD standard mandatory elements should be present, but they are not sufficient. A competency model should include some ways to evaluate, certify, register and compare competencies (Fazel-Zarandi \& Fox, 2013). As mentioned before, competencies as natural language strings limit the computability by software systems. The context of acquisition and performance levels are also two very important elements that are not considered by the RCD specification (Rezgui et al., 2014). As for the HR-XML model, competencies can be anything, knowledge, skills, attitude, capacities or preferences. The notion of competency should be more precisely defined (Sicilia, 2005).

Economy and focus-A competency ontology should restrict the number of its elements so that it remains applicable without extensive time-consuming efforts by human educators or managers. The web-LOD provides a solution by providing links to various existing widely used vocabularies and ontologies with clear semantic definitions. These links must be present in the competency model. The ASN-DL applies this principle, but its view of a competency as a natural language statement makes things difficult for interpretation by humans and for software processing. ASN-DL works around this problem by providing elaborated sets of relationships between competencies and between competencies and learning resources. In practice, the identification of all these relationships requires too much interpretation work by humans. We believe that the competency should be defined in a more structured way as proposed by the COMP1 and Rezgui ontologies, in order to restrict the number of relationships to document.

Flexibility-Not all uses of a competency ontology require the same amount of precision. One should be able to use the ontology with a limited part of its components when no more is required and use a larger set of components if the full power of expressivity is needed. A way to achieve this it to organise the ontology model in stages, from a simple core level to various larger sets of the model elements.

Genericity-Finally, the competency model should be generic, using terms and relations that are not too closely related to particular specialized contexts. The model should be widely applicable, interacting if needed with other more specialized vocabularies of the web-LOD that extend the competency vocabulary to provide a specialized application context.

\section{COMP2, a new competency ontology}

Based on the previous discussions and analysis, we now present the COMP2 competency ontology. COMP2 is structured into five stages each adding more and more elaborated vocabulary elements.

\section{Stage 1-core competency model}

The Core COMP2 model offers a structural description for competencies to be used in any educational applications. We have maintained the COMP1 method to decompose a 


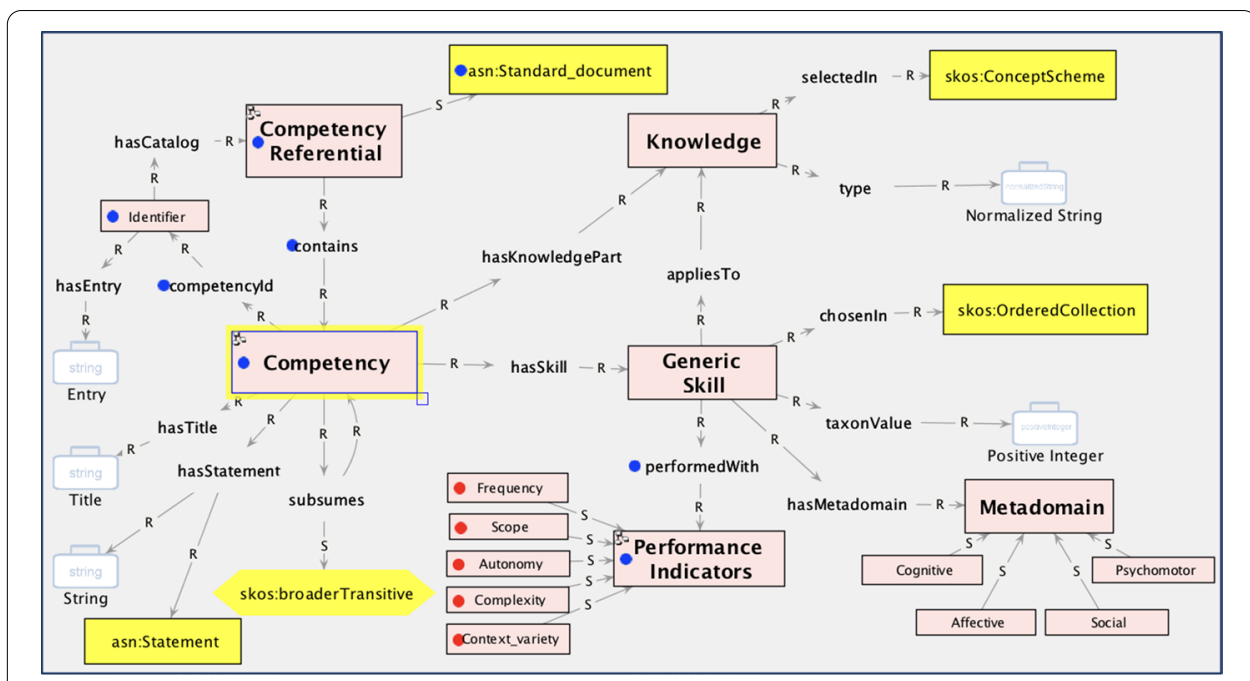

Fig. 3 The Core COMP2 competency model

natural language competency statement into three structural parts: skill, knowledge and performance. The generic skill and knowledge parts of a competency are both mandatory while the use of performance indicators is optional, but adds precision to a skill.

The central Competency class shown on Fig. 3 now includes the mandatory properties in the RCD information model: competency title and identifier related to a catalog term and an entry in this catalog. As catalog we use the class Competency referential, that corresponds also to the ASN-DL standard document class. This link can be used to provide more detail on the origin of a competency profile by using some of the more precise ASN-DL constructs. A competency has an associated Statement, which is a natural language string. These elements are all mandatory. There is a subsumes property between competencies, which is a specialization ( $\mathrm{S}$ link) of a SKOS:broaderTransitive propery. This relation is optional and we do not need more relations between competencies.

The Generic Skill component of a competency is chosen in a skos:OrderedCollection of terms (a list). Each skill has a position (taxonValue) in this ordered collection and a property that specifies its Metadomain class: cognitive, affective, social or psychomotor. In (Author, ref 6), we have presented and justified a skill's taxonomy that applies to all four metadomains. The widely used notion of "Attitude" is considered as an Affective skill or a Social skill, depending on the context of use. See also (Romiszowski, 1981) for the integration of skills from various metadomains.

Users can choose a skill in any ordered collection, for example a four-level ordered collection (receive, reproduce, produce/create, self-manage) or in a more detailed tenlevel list (acknowledge, remember, specify, translate, apply, analyze, repair, synthesize, evaluate, self-control). In COMP2 we provide flexibility by leaving the choice of the skill's taxonomy to each specific use. For example, one can use the Bloom (1956) taxonomy for skills of the cognitive metadomain, and Krathwohl et al. (1964) taxonomy for skills of the affective metadomain (sometimes called "attitudes"). 


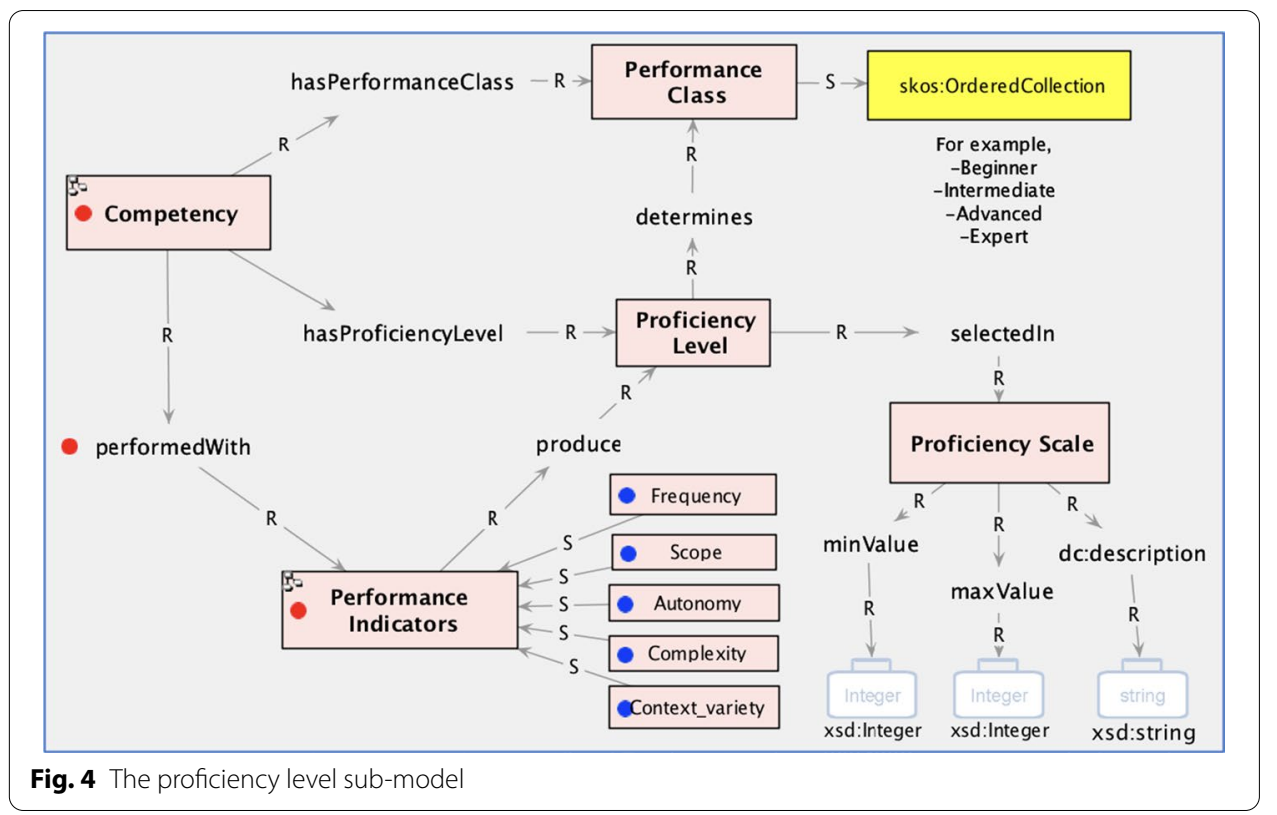

The skill part in a competency applies to some Knowledge part selected in a skos:ConceptScheme (a Knowledge domain model). The application of the skill to the knowledge part can be performed with some optional Performance indicators, that will be further described in stage 2 of the ontology.

We do not include in this first stage model important notions like proficiency scale, competency weight, evidence record or contextual information because they are not needed in many of the applications. The notion of a map of statements with multiple statement relationships and statement properties, as proposed in the ASN-DL model, is not retained in COMP2 but it is possible to extend the competency profile by using the optional S link to ASN-DL elements.

\section{Stage 2-extension to competency performance and proficiency levels}

The stage 2 extension adds (as a sub-model of stage 1) the classes and properties shown on Fig. 4, which are needed to define a proficiency level and a performance class.

These concepts are based on five performance indicators: Frequency, Scope, Autonomy, Complexity and Context_variety. We propose here to combine the value of these performance indicators, as we have done in some applications, to produce a proficiency level selected in a proficiency scale. Such a scale is described by three properties: a $d c$ :description (a string value), and two integers, a minValue and maxValue. For example a user can select a numeric scale from 0 to 100 or a Likert scale from 1 to 5 . Then, by fixing intervals on that scale, the proficiency level determines a Performance_class for the competency, which is a skos:OrderedCollection, for example: beginner, intermediate, advanced, expert or simply D, C, B, A.

These elements enable for example the classification of courses or learning activities or modules into various achievement levels indicated by the performance class associated to a target competency. 


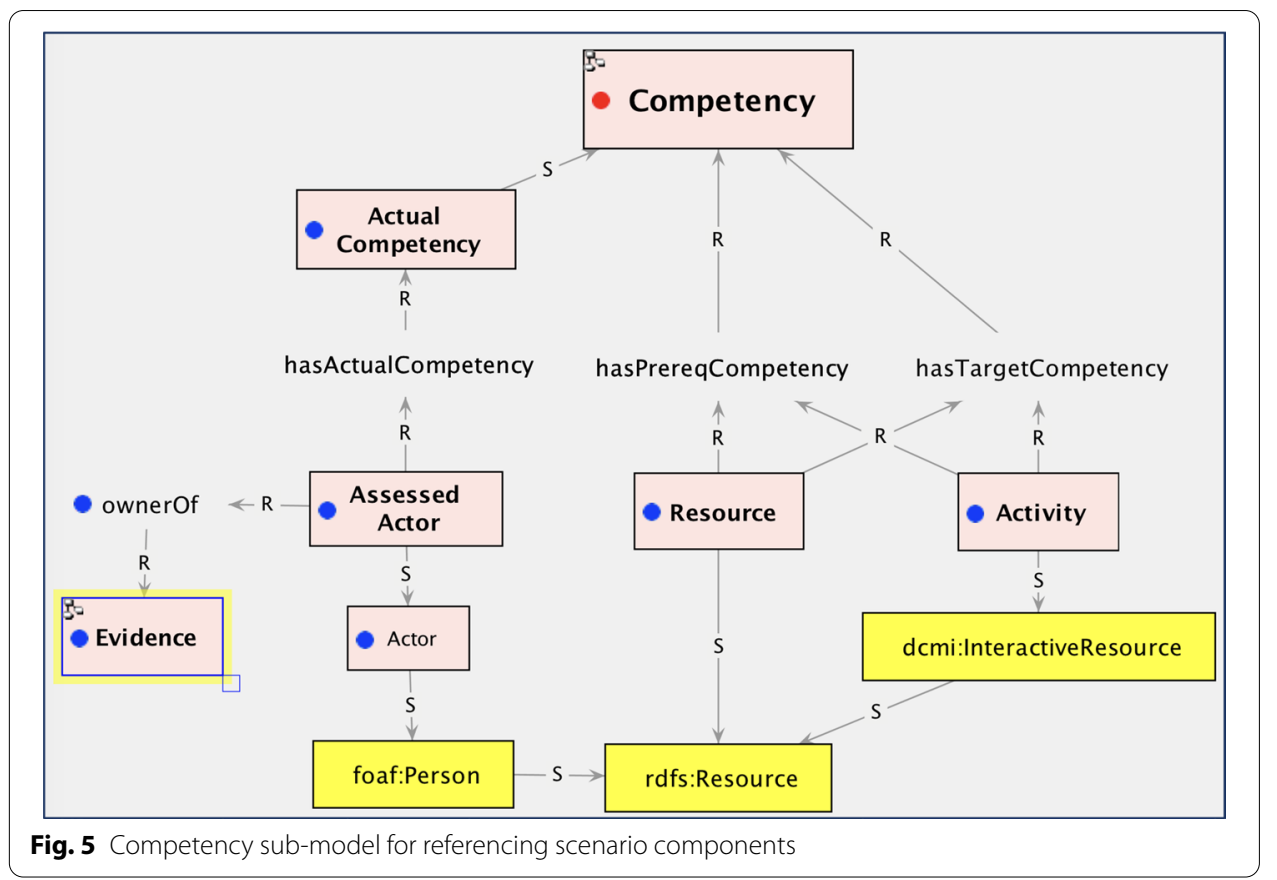

Stage 3-extension to competency referencing of actors, activities and resources

Competencies can serve to reference various elements composing learning scenarios in a course, a training program, a work scenario or a business process. Basically, in a scenario, actors (learners, workers, any foaf:person) achieve activities or tasks (dcmi:InteractiveResource) using and producing some resources ( $r d f s:$ Resource) that can be documents or all kinds or performances (like diving or dancing).

The model on Fig. 5 adds to the stage 1 model, independently of stage 2, the possibility to associate Competencies to Resources or Activities. A prerequisite competency property means that someone should have this competency to use the resource or engage in the activity. A target competency means that someone who has built or used such a resource or achieved such activity has demonstrated the corresponding target competency. The resource or the activity can then serve as Evidence that an Assessed Actor now owns an Actual Competency.

This sub-model provides classes and properties to implement a competency management process in a scenario. One possible application of the model is the identification of the actual competencies achieved by an Assessed Actor in a scenario. Another useful application might serve to analyse the coherence of a learning scenario by comparing the competencies assigned to input resources for an activity with the target competencies of this activity, in order to verify if the information provided for the activity is sufficient to enable its achievement by the target audience. In other applications, resources and activities can be recommended to actors by comparing their prerequisite and target competencies to the actor's actual competencies, which should be higher than the prerequisite but lower than the target competency. 


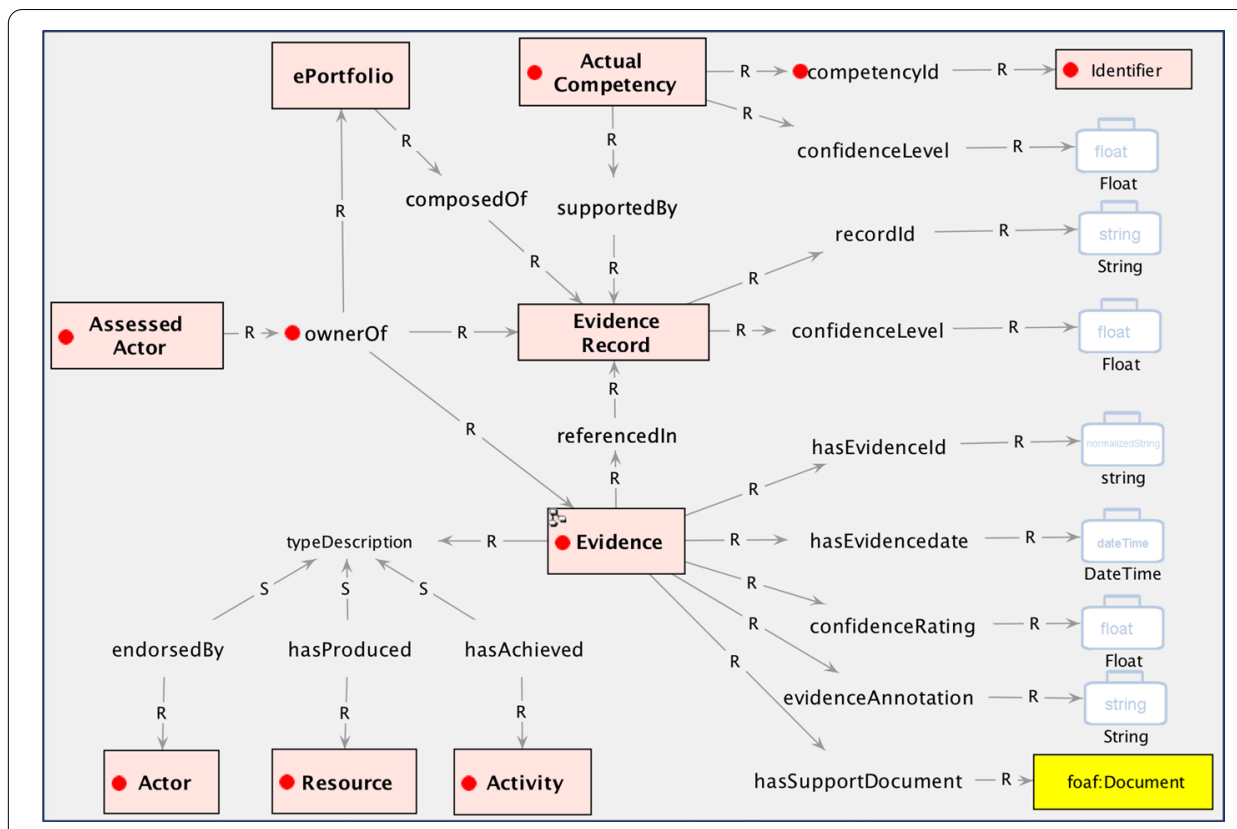

Fig. 6 Evidence sub-model for competency assessment

\section{Stage 4-extension to evidence records and portfolios}

The stage 4 extension of the COMP2 ontology presented on Fig. 6 is centered on the Evidence class. Evidences owned by an Assessed actor are grouped in Evidence Records that testify of the acquisition of an actual competency by this actor.

Each Evidence record can group a number of particular Evidence, all related to the same Actual Competency. Each Evidence can be part of an ePortfolio that groups all the actual competencies of the assessed actor together with its evidence records. An Evidence can thus serve in more than one evidence record if it is associated to more than one competency. As in the Rezgui model, an Evidence record has a ConfidenceLevel that can be calculated from the ConfidenceRatings of all the evidences in the record. Each evidence has a date, a confidence rating, an annotation that describes it, and a typeDescription, which can be an endorsement by an actor (including him/herself), a resource produced (including an exam or an essay) or an activity or task achieved by the assessed actor.

Furthermore, an Evidence can have a Support Document (any foaf:Document) that displays the evidence, for example a document produced by the learner, an Open badge (Open Badges, 2020) or an endorsement letter or email from an evaluator. The support document can also describe the context of acquisition of this evidence. Contrary to the Rezgui model, we limit the concept of context to evidence acquisition instead of competency acquisition. Competency acquisition is a long term process that can occur in a variety of acquisition contexts. The context of acquisition will influence confidence rating which will ultimately help set the confidence level of the evidence and also of an actual competency. 


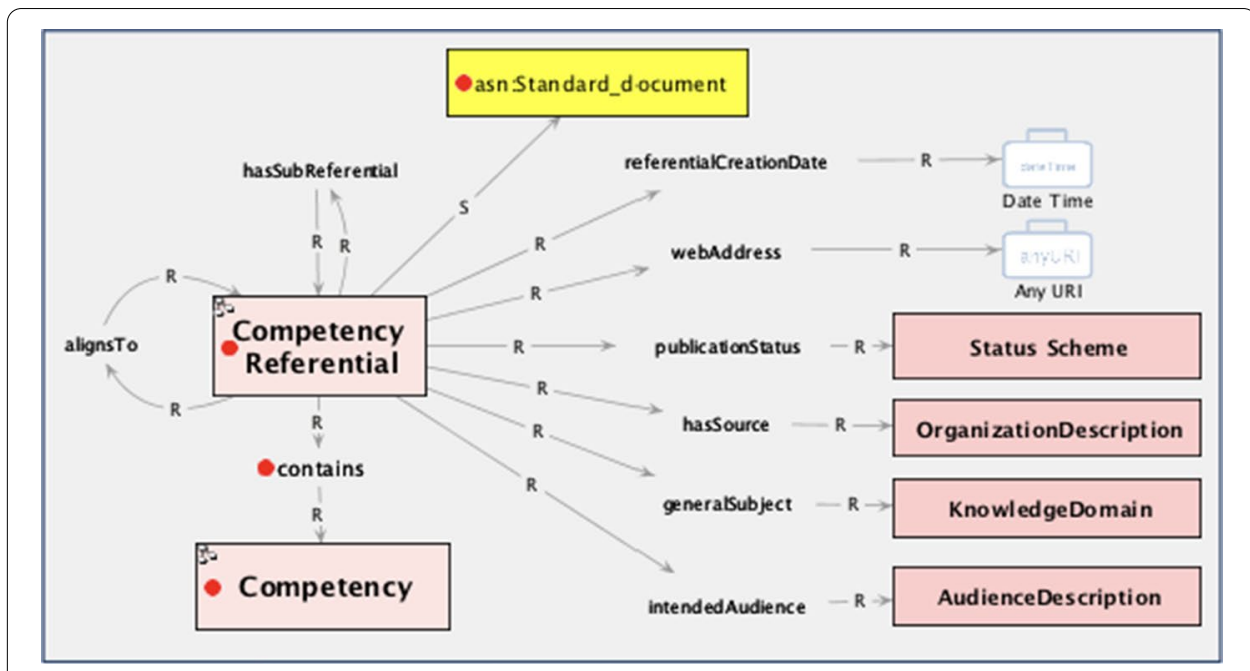

Fig. 7 Competency referential information sub-model

\section{Stage 5-extension to contextual provenance information}

We provide a last extension for the contextual provenance information of a competency referential, in order to compare and align competencies from different sources. Here we adapt some of the properties for standard documents in the ASN-DL model, while keeping an external S link to the ASN-DL Standard Document class to facilitate more elaborated descriptions using the ASN-DL model if needed.

As shown on Fig. 7, a Competency Referential, that contains one or more competencies, can be subdivided in a tree of modules or competency sections by the hasSubReferential property. It can also be associated with other competency referentials by an alignsTo property. In addition, the competency referential has a number of properties for its creation date, its web address, its publication status, its source (the publisher), its general subject and its intended audience, encompassing the "User Area" information in the HR-XML model.

\section{Competency-based personalization of learning environments}

The Competency Ontology presented above can serve in many kinds of competencybased educational applications (Colson and Hirumi, 2016; Krause et al., 2015; Norman et al., 2014). In this section, we only focus on a very important set of applications where the goal is to personalize on-line learning environments. Personalization aims to adapt the activities and resources proposed to learners in an on-line learning scenario, according to their knowledge and skills, in other words to their actual competencies (Authors, ref 5). It is of particular importance for example, in Massive Open Online Courses (MOOC), where the same course is followed by thousands of learners, all with different background, knowledge and culture, making it impossible, to provide efficient one-sizefits-all learning environments (Authors, ref 8). 


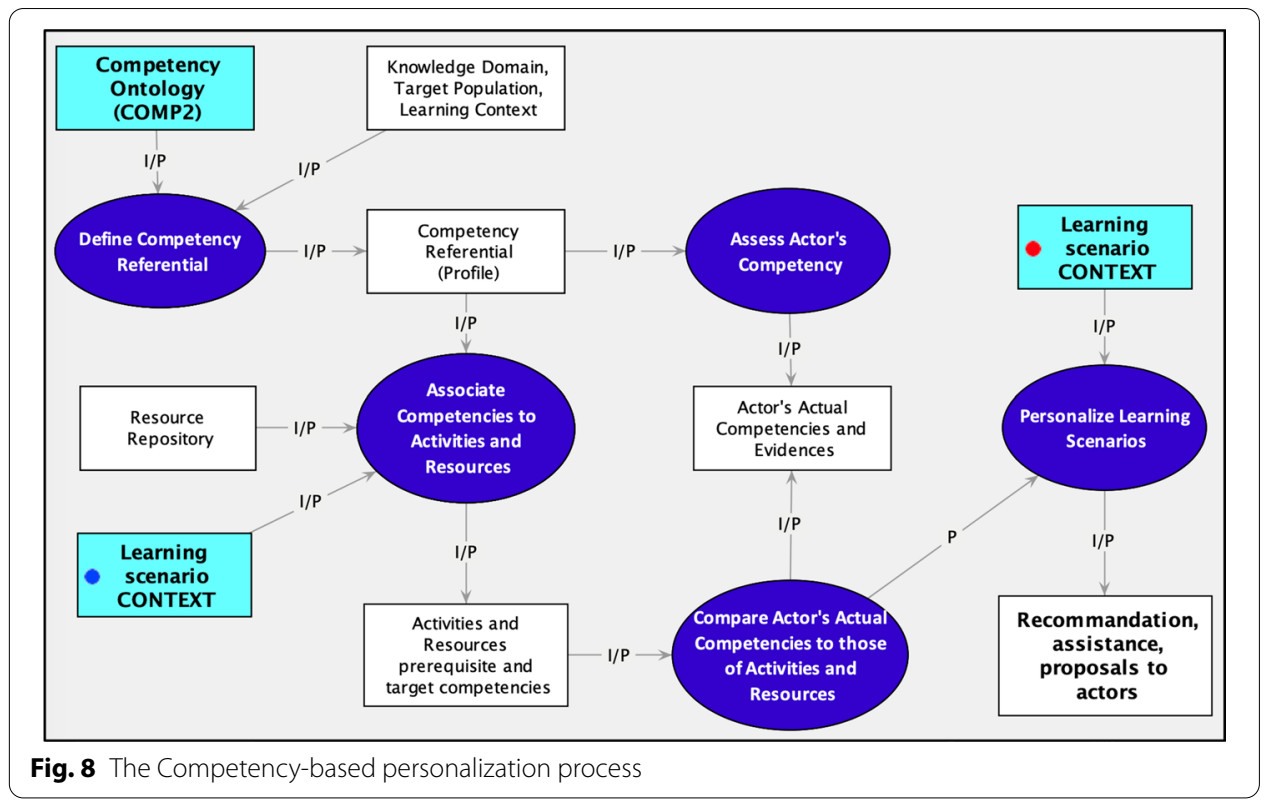

In this section, we will present an illustrative example for three of the main steps of the competency-based personalization process using the COMP2 ontology. This example has been tested within the TELOS system to which a Knowledge and Knowledge Referencing System (KRS) and a set of Semantic Searching Tools (SST) had been added. (Authors, ref 7). ${ }^{6}$

\section{Specifying a competency referential}

The general process for competency-based personalization of learning environments is schematized in Fig. 8. The role of the COMP2 ontology is to provide a generic schema that serves to define a particular competency referential for a learning environment or a work process.

Competency referentials are built by a process that starts with the COMP2 ontology model that structures the concepts, properties and individuals in the subject domain of the learning environment. The left part of Fig. 9 shows a part of a Solar system ontology describing this domain's concepts (rectangles) and properties (hexagons) as well as individual (cut corner rectangues) planets and satellites. Once translated into RDFS format, this ontology schema provides a collection of RDF triples each displaying a property with its domain and range (concept or value), such as (Solar_system_planet, hasAtmosphere, Planet_atmosphere) or (Solar_system_planet, hasOrbitalPeriod, days).

Concepts, properties or RDF triples of the solar system ontology provide the knowledge part of a COMP2 competency. Then, a tool enables to associate generic skills and performance indicators and levels to some of this knowledge to complete the specification of a competency. The right part of Fig. 9 is a screen of the TELOS Competency

${ }^{6}$ A description of the TELOS system and of these tools can be found in (Authors: Enhance TELOS Learning System with Ontology-based Referenced Resources). 


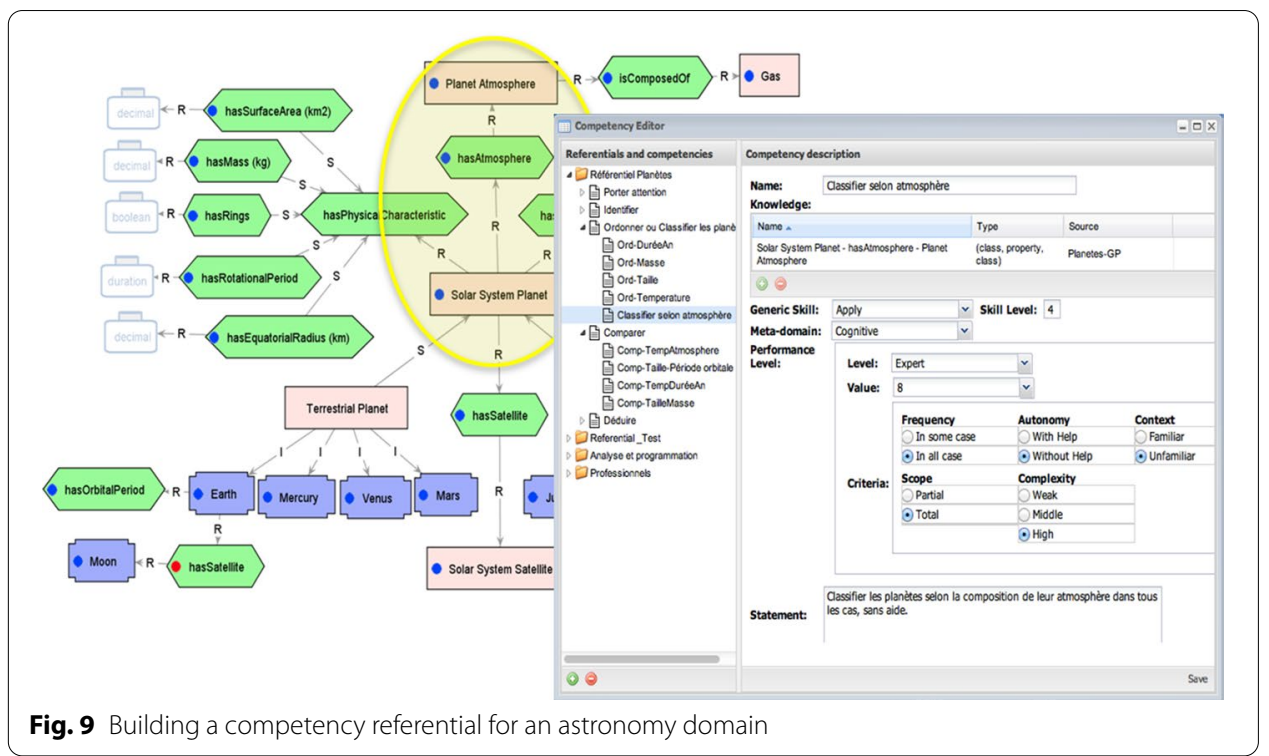

editor where the left panel shows the Planet competency referential with five groups of competency defined by different skill levels. Actually, the "Classify according to atmosphere" competency is selected.

The right panel presents the definition of this competency. Here are indicated the name of the competency (in french), the RDF triple that has been selected as the knowledge part, and the Generic skill part, "Apply" set at level 4 of the skill's ordered collection and specified in the cognitive meta-domain. The following step enables the user to select values for the five performance criteria. These values combine automatically to set the performance level as expert, level 8 in a performance scale. Finally, a natural language statement of the competency summarizes all these elements.

Here we have used the Core COMP2 model (Fig. 3) and the proficiency sub-model (Fig. 4). This has set this competency at a $(4,8)$ level in a two dimension scale (skilllevel X performance-level), a metric used later in the process.

\section{Competency referencing of learners, activities and resources}

Competencies in a referential can then be associated to actors (learners, tutors, ...), documents and activities according to the COMP2 sub-model for referencing (Fig. 5), in order to enable search and/or recommendation of personalized resources.

Competency descriptors are linked to TELOS resources by means of three properties: hasActualCompetency that specifies the current competencies of actors; hasPrerequisiteCompetency and hasTargetCompetency that specify the prerequisite and target competencies of resources (e.g. documents, activities) other than actors. Once the competence descriptors are added to a resource, they are permanently stored in the technical ontology of TELOS. The system can then make inferences using them.

Each particular competency associated to a learner results from a competency assessment processes that sets the learner's actual competencies at the start of the 
learning environment. If no adequate competency record exist for a learner, as is most often the case, assessment activities can be added at the beginning of the learning scenario, for example a Competency-based questionnaire, that will set the initial competency level of each learner. As the learner progresses, the automatic assessment process is constantly identifying supporting pieces of evidence from the execution of the scenario by the learner: exams or tests passed, documents produced, activities succeeded, appraisal by other individuals, etc., as mentioned in the COMP2 evidence sub-model (Fig. 6).

In parallel, the same Competency referential serves to reference activities/tasks and resources in a learning environment with prerequisite and target competencies from this referential. When an activity or resource is achieved, used or produced by a learner, its target competencies is added to the learner's actual competencies and the activity or resource is added as evidence of this new learner's competency, enriching the user model and populating his/her eLearning scenario.

\section{Competency-based search and recommendation}

A competency comparison algorithm enables the inference of a competency gap or of an alignment between an actor's actual competency and the prerequisite and target competencies of the activities or resources that he executes or consults (Authors, ref 5). These comparisons serve to provide recommendations to learners or facilitators as to which activities or resource to use in a personalized learning environment. The goal here is to identify relevant resources according to an actor's actual competency.

In TELOS, it is possible to search for semantically close resources by a request that triggers an inference in the TELOS technical ontology. Consider two competencies $\mathrm{C} 1=(\mathrm{K} 1, \mathrm{~S} 1, \mathrm{P} 1)$ and $\mathrm{C} 2=(\mathrm{K} 2, \mathrm{~S} 2, \mathrm{P} 2)$ with their knowledge, skill and performance parts, $\mathrm{C} 1$ serving as a request and $\mathrm{C} 2$ as the search target. The semantic neighborhood between $\mathrm{C} 1$ and $\mathrm{C} 2$ is calculated according to the position of their knowledge part (K1 and K2) in the domain ontology and to values of their skill levels (S1 and S2) and performance levels (P1 and P2). Users can ask to find a resource (or an actor) with associated competencies identical, very close, close, or distant from the requested one. They can also request for a higher or lower skill/performance requirement, or for a more generic or more specific resource according to the knowledge components of the request.

Competency comparison can be applied to various personalization situations (Authors, ref 5):

- scenario designers may perform a semantic search in order to identify relevant resources to be added as inputs to specific learning activities, possibly offering various choices to different subgroups of learners each with similar actual competencies;

- learners performing an activity may need to identify activities or resources that can help them to complete an activity or to identify peer helpers or tutors whose actual competency is the same or higher than the competency targeted by this activity; 
- recommendation agents can check if a learner has the prerequisite competency associated to an activity, and advise him/her automatically to do a preliminary activity or to consult some resources having a target competency semantically very close to the prerequisite competency.

\section{Conclusion and future work.}

In all fields of education (CAEL, 2017; Colson and Hirumi, 2016; Krause et al., 2015) and human resource management (Dorn et al, 2008; Elia and Marguerita, 2015), competency definitions play essential roles. They provide clear objectives for learning or knowledge-based work processes. They help focus on the right knowledge to consider and the right strategies to employ. They are an essential pieces of user models and e-portfolios showing evidence of competency acquisition. They provide a basis to evaluate a person's performance and to personalize learning or working activities. Within competency management processes, some tasks can be performed by computer programs and others by human tutors or managers.

In this paper, we presented the process and the result of creating the COMP2 competency ontology. This semantic web based ontology was built on our own previous work on competencies and by taking into account four other generic models. COMP2 provides a general information model for defining competency referentials, linked to other widely-used semantic vocabularies present in the web-LOD. It provides a solid basis to build competency-based learning or working environments. Part of the model has been applied in previous projects (Author, ref 6).

The competency referentials (or profiles) produced using the COMP2 ontology have a precise meaning readable by humans for design, evaluation and communication purposes. The COMP2 ontology provides also processing capability to machines that translates to standard RDFS code for interconnection within the web-LOD. By its links to other competency vocabularies and ontologies, COMP2 displays a sufficiently large scope to cover all the necessary components of competency referentials, while keeping a manageable size and focus. This is achieved by a five-stage competency ontology with a mandatory core model and other optional stages sub-models to be added as needed by the application context.

Following work should focus on new implementations of the COMP2 ontology for the design of web-based learning environments. We aim to integrate the COMP2 ontology into a new Instructional engineering method, called MIENA, that we are actually designing. This will include research on competency evaluation processes to support the personalization of learning scenarios for MOOC environments (Authors, ref 8; Authors, ref 9).

Another important direction should focus on a technical definition of the COMP2 ontology enabling its publication in a vocabulary/ontology referential such as the Linked Open Vocabularies (LOV, 2017), which already contains 617 vocabularies. These and many other vocabularies in the Linked Data Cloud (LOD, 2017) could be usefully connected to the COMP2 ontology to increase its use for instructional design or knowledge management engineering. 
A more extensive evaluation of the COMP2 ontology will have to be conducted. At present it has only been validated partially through its use in small applications similar to the one presented in "Competency-based personalization of learning environments" section. A larger evaluation is needed, based for example on the five knowledge representation principles of (Davis et al., 1993), in a way similar to the one taken by these authors to validate the GaTO Ontological model (Dermeval et al., 2019).

\begin{abstract}
Abbreviations
ASN-DL: Achievement Standards Network Description Language; COMP1: Competency Ontology 1 (our non-SW competency model); COMP2: Competency Ontology 2 (our new SW competency model); DCMI: Dublin Core Metadata Initiative; FOAF: Friend of a Friend; GMOT: Graphic Modeling Object Tool; HR-XML: Human Resource Extensible Markup Language; KG: Knowledge Graph; KRS: Knowledge Referencing System; LOD: Linked Open Data; LOV: Linked Open Vocabularies; MIENA: Méthode d'ingénierie d'environnements numériques d'apprentissage (french abbreviation); MISA: Méthode d'ingénierie de systèmes d'apprentissage (french abbreviation); OWL: Ontology Web Language; RCD: Reusable Definition for Competencies; RDCEO: Reusable Definition for Competencies and Educational Objectives; RDFS: Resource Description Framework Schema; SKOS: Simple Knowledge Organization System; SST: Semantic Searching Tools; SW: Semantic Web; TELOS: Technology-enhanced Learning Operating System; URI: Uniform Resource Identifier; Web-LOD: The Web of Linked Open Data; XML: Extensible Markup Language.
\end{abstract}

\title{
Acknowledgements
}

Not applicable.

\section{Authors' contributions}

GP has modeled the ontologies reported in the paper and written the first version of the manuscript. OM has written parts of the final manuscript and added references. RB has done the preliminary documentary research. Authors have read and approved the final manuscript.

\section{Authors' information}

Gilbert Paquette is a researcher at the LICEF Research Center for cognitive informatics and educational applications he has founded in 1992, emeritus professor at Télé-université du Québec, GP holds a Ph.D from the Université du Maine (France) in Artificial Intelligence and Education. He has held a Canada Research Chair in Cognitive and Educational Engineering and acted as the Scientific Director of the LORNET Canadian research network. In 2007, he has received an Honoris Causa Doctorate from the University Pierre et Marie Curie (Paris VI). He has pioneered strategic projects in the field of knowledge-based systems, instructional engineering and distance education. Recent publications include four books on technology-based learning and a number of contributions to education technology journals.

Olga Marino is a Computer Scientist professor from the University of Los Andes in Colombia, she has a PhD in Artificial Intelligence from the University Joseph Fourier in France. For more than ten years, she has been Professor of the School of Engineering at the University of Los Andes and Director of the Laboratory on Technology Enhanced Learning, LIDIE, and later on Professor at the TELUQ and researcher at LICEF. In 2005 Olga Marino won the Prize of the Minister of Education of Quebec. Since 2012, she is Associate Professor for the Systems and Computing Engineering Department of her university in Bogota, Colombia where she is member of the School of Engineering research Committee, member of the research group on Foundations, Languages, Al and bioinformatics, FLAG and member of the Center for Research and Formation in Artificial Intelligence, CINFONIA. Her research interests include semantic web, recommender systems, personalization, ontological engineering, technology enhanced learning, learning analytics, smart learning environments.

Rim Bejaoui is a post-doctoral student at LICEF Research Center, she has conducted research on the personalization of on-line education. She has developed an advisory system for designers to help them builf personalized massive on-line open courses. She has also conducted work in instructional engineering based on competency profiles.

\section{Funding}

Not applicable.

\section{Availability of data and materials}

Not applicable.

\section{Declarations}

Competing interests

The authors declare they have no competing interests.

\section{Author details}

${ }^{1}$ Laboratory for Instructional and Cognitive Engineering (LICE), LICEF Research Center, Université TÉLUQ, Quebec, Canada.

${ }^{2}$ TICSw Research Group, Systems and Computing Engineering Department, School of Engineering, Universidad de los

Andes, Bogota, Colombia. 
Received: 15 December 2020 Accepted: 19 August 2021

Published online: 31 August 2021

\section{References}

Allemang, D., \& Hendler, J. (2011). Semantic web for the working ontologist-Effective modeling in RDFS and OWL (2nd ed.). Morgan-Kaufmann/Elsevier.

Allen, C., Bloom, N., Bork, D., Kiel, P., Scott, D., Edwards, J. D., Cohn, D., Bartkus, K., Mickley, R., Kortright, E. \& Weiss, J. (2001). HR-XML competencies 1.0 (measurable characteristics) recommendation. Retrieved March 14, 2017 from http://xml. coverpages.org/HR-XML-Competencies-1_0.pdf.

ASN-DL. (2012). Achievement standards network core RDF. Retrieved March 14, 2017 from http://standards.asn.desire2lea m.com/index.php?title=ASN_Vocabulary.

Author (ref 1). Modélisation des connaissances et des compétences: un langage graphique pour concevoir et apprendre.

Author (ref 2). Instructional engineering for network-based learning.

Author (ref 3). An ontology and a software framework for competency modeling and management.

Author (ref 4). A competency-based ontology for learning design repositories.

Authors (ref 5). Competency comparison relations for recommendation in technology enhanced learning scenarios.

Author (ref 6). Visual knowledge and competency modelling-From informal learning models to semantic web ontologies.

Authors (ref 7). Enhance TELOS learning system with ontology-based referenced resources.

Authors (ref 8). Competency-based personalization for massive online learning.

Authors (ref 9). Cadre d'analyse de la personnalisation de l'apprentissage dans les cours en ligne ouverts et massifs (CLOM).

Authors (ref 10). TELOS—An executable model for virtual campus environments.

Berners-Lee, T., Hendler, J., \& Lassila, O. (2001). The semantic web. Scientific American, 284(5), 34-43.

Bloom, B. S. (1956). Taxonomy of educational objectives: The classification of educational goals. Handbook I: Cognitive domain. Longman.

Braun, S., Kunzmann, C., \& Schmidt, A. P. (2012). Semantic people tagging and ontology maturing: An enterprise social media approach to competence management. International Journal of Knowledge and Learning, 8(1-2), 86-111.

Breuker, J., \& Van de Velde, W. (1994). Commonkads library for expertise modelling—Reusable problem solving components. Amsterdam: IOS Press.

CAEL. (2017). Competency-based education. https://www.cael.org/blog/topic/competency-based-education-cbe, consulted June, 2018

Casellas, N. (2011) Methodologies, tools and languages for ontology design. In Legal ontology engineering. Law, governance and technology series (vol 3). Springer. https://doi.org/10.1007/978-94-007-1497-7

Chandrasekaran, B. (1987) Towards a functional architecture for intelligence based on generic information processing tasks. In Proceedings IJCAI-87 (pp. 1183-1192), Milan, Italie.

Colson, R., \& Hirumi, A. (2016). A framework for the design of online competency-based education to promote student engagement. In Handbook of research on competency-based education in university settings (p. 168), Rasmussen, Karen,Northrup, Pamela, Colson, Robin.

da Silva, F. P., Jerónimo, H. M., \& Rino Vieira, P. (2019). Leadership competencies revisited: A causal configuration analysis of success in the requirements phase of information systems projects. Journal of Business Research, 101(6), 88-96.

Davis, R., Shrobe, H., \& Szolovits, P. (1993). What is a knowledge representation? Al Magazine, $14,17$.

DCMI. (2012). Dublin core metadata terms (No. 14 june 2012 edition). http://dublincore.org/documents/dcmi-terms/.

Dermeval, D., Albuquerque, J., Bittencourt, I. I., Isotani, S., Silva, A. P., \& Vassileva, J. (2019). GaTO: An ontological model to apply gamification in intelligent tutoring systems. Frontiers in Artificial Intelligence, 2, 13. https://doi.org/10.3389/frai. 2019.00013

Dolog, P., \& Schäfer, M. (2005). A framework for browsing, manipulating and maintaining interoperable learner profiles, Lecture Notes in Artificial Intelligence., 3538, 397-401.

Domingue, J., Fensel, D., \& Hendler, J. A. (Eds.). (2011). Handbook of semantic Web technologies. Springer-Verlag.

Dorn, J., Pichlmair, M., Schimper, K., \& Tellioglu, H. (2008). Supporting competence management in software projects. In Technology Management Conference (ICE), 2008, IEEE International (pp. 1-8). IEEE. Retrieved March 13, 2017 from http://ieeexplore.ieee.org/abstract/document/7462044/.

Dubois, D., Shadden, M., Kaufman, R., \& Brethower, D. (2000). The competency casebook: Twelve studies in competencybased performance improvement. Performance Improvement, 39(1), 37-40.

Elia, G., \& Margherita, A. (2015). Next-generation human resource management: A system for measuring and visualising professional competencies. International Journal of Human Resources Development and Management, 15(1), 1-15.

Fazel-Zarandi, M., \& Fox, M. S. (2013). Inferring and validating skills and competencies over time. Applied Ontology, 8(3), 131-177.

FOAF. (2014). FOAF vocabulary specification 0.99—Namespace document 14 January 2014_Paddington Edition. http:// xmlns.com/foaf/spec/20140114.html.

Gadušová, Z. (2019). Teachers' professional competence and their evaluation. Education and Self Development, 14(3), $17-24$.

Gruber, T. (1993). A translation approach to portable ontology specifications. Knowledge Acquisition, 5(2), 199-220. https://doi.org/10.1006/knac.1993.1008

Hattingh, M., Marshall L., Holmner, M. \& Naidoo, R. (2019). Data science competency in organisations: A systematic review and unified model. In ACM international conference proceeding series. ACM Digital Library. Retrieved November 20, 2019 from https://dl.acm.org/citation.cfm?id=3351110 
Heath, T., \& Bizer, C. (2011). Linked data: Evolving the Web into a global data space. Synthesis Lectures on the Semantic Web: Theory and Technology, 1, 1-136.

Idrissi, M. K., Hnida, M., \& Bennani, S. (2020). Competency-based assessment: from conceptual model to operational tool. In I. Management Association (Ed.), Learning and performance assessment: Concepts, methodologies, tools, and applications (pp. 108-129). Hershey: IGI Global. https://doi.org/10.4018/978-1-7998-0420-8.ch006

IEEE RCD. (2004). IEEE Draft Standard for Learning Technology — Standard for Reusable Competency Definitions (p. 32 pages). Three Park Avenue New York, NY 10016-5997, USA: Institute of Electrical and Electronics Engineers, Inc. http://group er.ieee.org/groups/ltsc/wg20h/files/IEEE_1484.20.WD_01_rough.pdf.

IEEE RCD. (2007). IEEE standard for learning technology-data model for reusable competency definitions (pp. 1-36). Aprouved 27 September 2007 by the IEEE-SA Standards Board. https://www.doleta.gov/usworkforce/pdf/2007-ieeecomp.pdf.

IMS RDCEO. (2002). IMS reusable definition of competency or educational objective specification. IMS Global Learning Consortium Inc. https://www.imsglobal.org/content/rdceo-v1.

Krathwohl, D. R., Bloom, B. S., \& Masia, B. B. (1964). Taxonomy of educational objectives: The classification of educational goals. Handbook Il: Affective domain. Longman.

Krause, J., Dias, L. P., \& Schedler, C. (2015). Competency-based education: A framework for measuring quality courses. Online Journal of Distance Learning Administration, 18(1), 1-9.

Le Boterf, G. (1999). Lingénierie des compétences (2ème édition) (Éditions d'organisation). Paris, France. Retrieved September 25, 2017 from https://www.decitre.fr/livres/l-ingenierie-des-competences-9782708122482.html.

LOD. (2017). The linking open data cloud diagram. Retrieved October 19, 2017 from http://lod-cloud.net.

LOV. (2017). Linked open vocabularies. Retrieved October 19, 2017 from http://lov.okfn.org/dataset/lov/.

Moulet, L., Marino, O., Hotte, R., \& Labat, J. M. (2008). Framework for a competency-driven, multi-viewpoint, and evolving learner model. In B. P. Woolf, E. Aïmeur, R. Nkambou, \& S. Lajoie (Eds.), Intelligent tutoring systems. ITS 2008. Lecture notes in computer science (Vol. 5091, pp. 702-705). Springer.

Norman, G., Norcini, J., \& Bordage, G. (2014). Competency-based education: Milestones or millstones 1? The Accreditation Council for Graduate Medical Education Suite 2000, 515 North State Street, Chicago, IL 60654. https://doi.org/10. 4300/JGME-D-13-00445.1

ONTOTEXT. (2017). What are linked data and linked open data? https://ontotext.com/knowledgehub/fundamentals/ linked-data-linked-open-data/. Last consulted June 2019.

Open Badges. (2020). Open Badges home page. Retrieved March 22, 2020 from https://openbadges.org.

Princy, A. S., \& Rajeswari, M. (2019). Assessing competency of community healthcare workers. International Journal of Innovative Technology and Exploring Engineering, 8(10), 377-380.

RDFS. (2014). RDFS schema 1.1, W3C recommandation, 25 February 2014. Retrieved March 6, 2017 from https://www.w3. org/TR/rdf-schema/.

Rezgui, K., Mhiri, H. \& Ghédira, K. (2014). An ontology-based approach to competency modeling and management in learning networks. In Agent and multi-agent systems: Technologies and applications (pp. 257-266). Springer. https:// doi.org/10.1007/978-3-319-07650-8_26

Romiszowski, A. J. (1981). Designing instructional systems. Kogan Page London/Nichols Publising.

SFIA. (2019). Skills framework for the information age. Retrieved December 10, 2019 from https://www.sfia-online.org/en.

Sampson, D. \& Fytros, D. (2008). Competence Models in Technology-Enhanced Competence-Based Learning. In Handbook on information technologies for education and training (pp. 155-177). Springer. https://doi.org/10.1007/ 978-3-540-74155-8_9

Sampson, D. G. (2009). Competence-related metadata for educational resources that support lifelong competence development programmes. Educational Technology \& Society, 12(4), 149-159.

Schmachtenberg, M., Bizer, C., \& Paulheim, H. (2014). Adoption of the Linked Data Best Practices in Different Topical Domains. In The semantic web_-ISWC 2014 (pp. 245-260). Presented at the International Semantic Web Conference, Springer, Cham. https://doi.org/10.1007/978-3-319-11964-9_16

Sicilia, M.-A. (2005). Ontology-based competency management: infrastructures for the knowledge intensive learning organization. In Intelligent learning infrastructure for knowledge intensive organizations: A semantic web perspective (pp. 302-324). Retrieved March 6, 2017 from https://www-igi-global-com.tlqprox.teluq.uquebec.ca/chapter/on...nagem ent/24420.

Sicilia, M.-A., Lytras, M., \& Jones, N. (2014). Using Ontologies for integrated knowledge management in organization design and engineering. In Organization design and engineering (pp. 202-228). Springer. https://doi.org/10.1057/ 9781137351579_9

SKOS (2009). SKOS simple knowledge organization system reference -W3C recommendation. Retrieved September 26, 2017 from https://www.w3.org/TR/2009/REC-skos-reference-20090818/.

Srivastava, S., \& Vikram, S. (2014). Understanding competencies and competency modelling-A Literature survey. IOSR Journal of Business and Management, 16(1), 14-22.

Suárez-Figueroa, M. C., Gómez-Pérez, A., \& Fernández-López, M. (2015). The NeOn methodology framework: A scenariobased methodology for ontology development. Applied Ontology, 10(2), 107-145.

Uschold, M., \& King, M. (1995). Towards a methodology for building ontologies. In Proceedings of IJCA195's workshop on basic ontological issues in knowledge sharing (Vol. 82, No. 1, pp. 74-82).

Yago, H., Clemente, J., \& Rodriguez, D. (2018). Competence-based recommender systems: A systematic literature review. Behaviour and Information Technology, 37(10-11), 958-977.

\section{Publisher's Note}

Springer Nature remains neutral with regard to jurisdictional claims in published maps and institutional affiliations. 